\title{
O REFERENCIAL TEÓRICO DE BOURDIEU E AS CONDIÇÕES PARA SUA APRENDIZAGEM E UTILIZAÇÃO*
}

Odaci Luiz Coradini**

SÍNTESE - Neste artigo são expostos alguns fundamentos da abordagem e da concepção de ciências sociais de Bourdieu, para, com base nisso, apresentar os problemas mais freqüentes nos esforços em sua aprendizagem e utilização. $\mathrm{O}$ argumento principal é o de que, se por um lado, o esquema analitico de Bourdieu pode representar um avanço para as ciências sociais, por outro lado, devido aos seus requerimentos quanto à aprendizagem e condições de exercicio profissional, frente à situação brasilẹira, apresenta também novos desafios e dificuldades.

\begin{abstract}
The paper exposes some fundaments of the approach and social science conceptualization of Bourdieu, followed by the presentation of the more common problems in their learning and application. The main argument is that at the same time that Bourdieu's analytical scheme may represent an advance ti the social sciences, due to its learning requirements and the existing conditions for the pratice of professional activity in Brazil, it also presents new challenges and difficulties.
\end{abstract}

A motivação inicial deste artigo foi uma palestra realizada pelo autor em maio de 1995 com o título de "O referencial teórico de Bourdieu e suas principais categorias de análise", na PUCRS. Tendo em vista a oportunidade e a atualidade de alguns temas conexos, especialmente alguns problemas comumente presentes em esforços da aprendizagem e domínio desta abordagem e sua utilização, nas condições culturais, institucionais e escolares encontradas no Brasil e nas quais ocorrem estes esforços, resolveu-se ampliar a temática e inclui-los.

\footnotetext{
- Há ainda uma série de outros problemas relevantes que mereceriam ser abordados, como, por exemplo, o das possibilidades e condições (ou não) de compatibilização do esquema analítico de Bourdieu com outros disponiveis; ou então, os problemas decorrentes das diferenças nos referenciais empíicos que estão na base das formulações daquele esquema, comparativamente às condiçōes encontradas no Brasil. Porém, tendo em vista o espaço disponivel, nos restringimos, neste texto, aos problemas comumente encontrados na utilização do esquema analítico de Bourdieu em nosso meio.

* Universidade Federal do Rio Grande do Sul, UFRGS.
}

\begin{tabular}{|l|l|l|l|l|l|}
\hline VERITAS & Porto Alegre & v. 41 & $\mathrm{n}^{\circ} 162$ & Junho 1996 & p. 207-220 \\
\hline
\end{tabular}




\section{1 - A concepção de "ciência do mundo social" de Bourdieu e as origens de alguns problemas em sua utilização}

Não se tem nenhuma pretensão de se fazer uma "apresentação" deste "referencial teórico", inclusive porque ela se tornaria "manualesca" e iria de encontro à própria concepção de seu autor relativamente ao ensino das ciências sociais. $\mathrm{O}$ objetivo principal deste artigo é destacar alguns elementos dos fundamentos da abordagem de Bourdieu que podem estar na origem de dificuldades em sua utilização, nas condições existentes no Brasil. ${ }^{1}$

Como qualquer abordagem, a de Bourdieu é o resultado de um conjunto de condições que abarcam diferentes niveis, ou seja, intelectuais, escolares e institucionais, existentes na França e em outros centros culturais nas últimas décadas. Suas bases epistemológicas e conceituais decorrem de suas estratégias de reelaboração e reformulação nos confrontos entre diferentes concepções de ciências sociais vigentes e por outro lado, de sua posição específica ao tentar enfrentar a "agenda de problemas" subjacente. Estas estratégias de contraposição e elaboração de uma nova "agenda de problemas", no entanto, não partem de um vazio, mas do conjunto de avanços e problemas então existentes. O que ocorre de novidade é a forma de repor estes problemas em novas bases, a partir de uma posição específica nestes confrontos. ${ }^{2}$

O que há de específico nesta posição? Mesmo sem a possibilidade de detalhálos, devem ser destacados alguns de seus fundamentos, tendo em vista o que é exposto adiante e, neste sentido, o primeiro elemento a ser destacado é o racionalismo como base para a concepção de ciências sociais. Obviamente, qualquer "ciência" que se pretenda como tal, inclusive as "sociais", tem no "racionalismo aplicado", de um modo ou de outro, seu fundamento. Mas no caso da abordagem de Bourdieu, é necessário especificar que não apenas se trata de um "racionalismo radical", como também é uma condição sine qua non e de modo exclusivo, o que tem uma série de implicações. Assim, neste esquema analítico, a única "utopia" aceita para as ciências sociais é a "utopia racionalista", ou seja, fica excluída como ilegítima qualquer relação com as mesmas enquanto busca de "sentido" ou "ontologia" ou então, tendo em vista algum objetivo "prático". ${ }^{3}$

Um segundo princípio básico, vinculado a esta exigência das ciências sociais enquanto "racionalismo aplicado", é sua autonomia frente às demandas e determinações sociais, até porque "não existem [...] demandas sociais por um saber total sobre o mundo social". Assim, nesta concepção, as ciências sociais somente podem se desenvolver na medida em que há "a autonomia do campo de produção científi-

1 Devido a isso, inclusive, não são abordadas as alterações pelas quais passou este esquema analitico no decorrer da carreira do próprio autor. Para tanto, podem ser consultados, entre outros, particularmente Bourdieu (1979, 1980 e 1987).

2 Quanto aos fundamentos epistemológicos e teónicos (a epistemologia de Bachelard, o estruturalismo lingüístico e de Lévi-Strauss, a sociologia de Marx, Durheim e Weber, etc.) e as apropriações e confrontos com outras abordagens, ver principalmente Le Sens Pratique (1980) e La Distinction (1979).

3 Para um maior aprofundamento destas formulações, particularmente no que tange aos fundamentos do campo cientifico e a diferença entre "autoridade científica" e "autoridade social" e os principios de sua legitimação, ver particularmente Bourdieu (1975, 1976, 1982b e 1986b). 
za" e dos "interesses específicos que se engendram no mesmo" (Bourdieu, 1982b: 26/32).

Embora o próprio Bourdieu reconheça que, de fato, a "sociologia partilha [...] de duas lógicas radicalmente discrepantes", ou seja, "a lógica do campo político" e a "lógica do campo científico" (Bourdieu, 1991: 376. Grifos no original), para o mesmo, as ciências sociais que dependem de outras determinações que não o próprio "racionalismo aplicado", ou seja, de "demandas externas", são deslegitimadas enquanto tais. Esta proposição de que a "autonomia" é uma condição sine qua non para o desenvolvimento (e para a própria existência) das ciências sociais, tem uma série de desdobramentos, que devem pelo menos ser esquematicamente elencados. Em primeiro lugar, a necessidade da ruptura com a "ilusão da transparência" e com as "prenoções" e, conseqüentemente, não apenas com a "compreensão imediata", mas também com as "questões" de cunho "cultural" ou das "filosofias sociais" ou as "questões últimas do futuro da civilização" (Bourdieu et al, 1968: 47/48). Desse modo, as "questões" postas pelos "intelectuais" ou pelos "produtores culturais" devem ser tomadas como objeto de estudo e não incorporadas como referenciais pelas ciências sociais. As ciências sociais não podem "comungar com seu objeto", para não sucumbirem na "complacência cúmplice pelas expectativas escatológicas" do "grande público intelectual". Isso inclui a renúncia tanto do profetismo, como da "lógica da relação entre o autor de sucesso e seu público" (Bourdieu et al, 1968: 47/48), ou seja, relações e legitimidade baseadas no "reconhecimento" e não no controle do campo científico pelos pares.

Nesta perspectiva, a única forma de as ciências sociais romperem com as prenoções e explicitarem os fundamentos das "visões e di-visões do mundo social", que são "culturais" (e portanto, "arbitrárias" e não "racionais") ou as bases culturais da dominação simbólica, é através da apreensão dos princípios que estruturam os respectivos illusio e doxas subjacentes às posições nos campos de luta (Bourdieu et al., 1968: 48). ${ }^{4}$ Em sintese, devido a este pressuposto da "autonomia do campo científico", uma das condições de existência da sociologia é a de "renunciar ao proveito social" e assim não "se servir da ciência ou do efeito da ciência para triunfar socialmente no campo científico" ou então, de fazer da "ciência do poder" um "instrumento de poder" (Bourdieu, 1984: 24 e passim), visto que o "poder social" tem outro fundamento e "racionalidade" que o "poder científico". A "lógica do campo científico", pelo menos em seus "estados mais avançados, conhece e reconhece somente a "força intrínseca da idéia verdadeira" e, portanto, na "comunicação científica" a "força dos argumentos" está "desvinculada de sua força social" (Bourdieu, 1991: 376).

Um terceiro princípio geral, decorrente deste requerimento de "autonomia" das ciências sociais, que também é uma condição sine qua non para esta abordagem, é a necessidade da "objetivação" do próprio "sujeito objetivante". Porém, não se trata apenas da necessidade de o sociólogo ter clareza e controle de suas "prenoções",

4 Sobre os fundamentos da análise sociológica da dominação e consagração cultural, das oposições entre a cultura dominante e a cultura escolar, ver particularmente Bourdieu (1979); sobre a análise dos determinantes sociais da filosofia, ver Bourdieu (1983) e sobre o confronto entre a sociologia e o campo político ou as vinculações de sua doxa com a chamada ciência política, ver, entre outros, particularmente Bourdieu (1988). 
"sentimentos", valores, preferências temáticas, etc. Esta objetivação abarca o sociólogo como "ser social" e as próprias condições de existência da sociologia e, portanto, o conjunto de determinações sociais por ele interiorizadas; em segundo lugar, as condições culturais e institucionais e os principios de classificação e legitimação subjacentes e que estão na base das possibilidades de existência das ciências sociais. Para tanto, "o sociólogo encontra armas contra os determinismos sociais na própria ciência", particularmente na "sociologia da sociologia" (Bourdieu, 1982b: 9). Entretanto, esta "sociologia dos determinantes sociais da prática sociológica", ou seja, a explicitação e controle de tudo aquilo que pode não ser "racionalismo aplicado", não se constitui em algo fácil e generalizável. Isso porque, além da mencionada autonomia das ciências sociais e da formação escolar e conseqüente "capital científico" necessários, esta "objetivação" pressupõe também que as ciências sociais não sejam utilizadas contra outros, nem como instrumento de defesa, "mas como arma contra si mesmo. Mas ao mesmo tempo, para ser capaz de utilizar a sociologia até o fim, sem se proteger demasiadamente, é necessário [...] estar numa posição social tal que a objetivação não seja insuportável" (Bourdieu, 1987: 38).

Em quarto lugar, esta concepção de ciências sociais pressupõe uma distinção rigorosa entre a "razão" e o "sentido prático" e por outro lado, a "lógica teórica" (esta, um "privilégio" do analista que, numa posição "externa", suspende sua "adesão primordial" e ontológica ao mundo social). Por sua vez, a "lógica prática" supõe sempre uma "economia das práticas" e um "sentido prático" na relação com o mundo social, ou seja, uma "socio-lógica", cuja confusão com a "lógica teórica" resulta no "intelectualismo" (projeção da posição do "intelectual") (Bourdieu, 1980: passim). Uma das principais decorrências disso para o cientista social é que esta "lógica teórica" requer uma forma de pensamento que pressupõe "uma reconversão de toda a visão ordinária do mundo social que se vincula unicamente às coisas visiveis" e "implica uma ruptura radical com a filosofia da história que está inscrita no uso ordinário ou semi-culto da linguagem [...] ou nos hábitos de pensamento associados às polêmicas da política"... (Bourdieu, 1982b: 32).

Mas esta distinção entre a "razão prática" e a "razão teórica" tem muitas outras decorrências, tanto em termos conceituais como metodológicos. Ocorre que, nesta perspectiva, não é o estatuto epistemológico que diferencia as ciências sociais das ciências da natureza, mas o fato de que diferentemente destas, o objeto das ciências sociais são "sujeitos classificantes". Conseqüentemente, é necessário "romper com a ambição, que é a das mitologias, de fundar na razão as divisões arbitrárias da ordem social e em primeiro lugar a divisão social do trabalho e dar assim uma solução lógica ou cosmológica ao problema da classificação dos homens", a qual "a sociologia deve tomar como objeto, em vez de se deixar tomar por ela", pois a "luta pelo monopólio da representação legítima do mundo social" e a "luta de classificações" é "uma dimensão" de qualquer luta (de classes, de idade, sexuais, etc.) (Bourdieu, 1982b: 14). Em síntese, as ciências sociais devem renunciar à pretensão de ser o árbitro das classificações sociais (por exemplo, "o conceito de classe", de "Estado", etc.) e tomar a lógica das próprias classificações e suas condições de objetivação social como objeto, com base numa posição "externa". Porém, não se trata apenas dos princípios de classificação e legitimação, mas também de sua objetiva- 
ção social nas lutas, nas instituições; na linguagem, nas filosofias e práticas sociais, e isso abrange inclusive as próprias divisões que atravessam as ciências sociais e suas utilizações nestas lutas.

O primeiro objetivo destes esforços é evitar a confusão entre a "razão prática" e a "razão teórica", com o conseqüente "intelectualismo" e em segundo lugar, através disso, estabelecer condições teóricas e metodológicas para a apreensão desta "razão" e "sentido prático". Dito de outro modo, nas ciências sociais, o "racionalismo aplicado" requer que ele seja aplicado inclusive contra si mesmo, tendo em vista evitar uma adesão "não racional" ao próprio "racionalismo", visto que se corre o risco de torná-lo "não reflexivo". É com base nisso que, mantendo a epistemologia do "racionalismo aplicado" de Bachelard, são formuladas as críticas ao "estruturalismo objetivista" de Lévi-Strauss (porém, mantendo sua abordagem "relacional"), ao "individualismo metodológico" ou "teoria da escolha racional", ao "positivismo", etc., ou seja, às abordagens unilateralmente "objetivistas", bem como, por outro lado, às abordagens "subjetivistas" ou "fenomenológicas"; visto que se trata de projeções "intelectualistas" do "sujeito objetivante" que não conseguiu se "objetivar", confundindo "objetivação sociológica" com "objetivação social"; ou então, no caso do "subjetivismo", que desiste de uma sociologia com base no "racionalismo" (Bourdieu, 1980: passim).

Isso conduz também, simultaneamente, à valorização de determinadas proposições de Weber (além de Wittgenstein, entre outros), como a noção de "estratégia", as condições de formação do "agente" (e não do "indivíduo") e suas relações com a "estrutura estruturante" (e não "estruturada"), as relações entre "sentido", "ação" e "recursos sociais", etc., ou seja, as condições sociais da produção do "pensável" e suas relações com o "dizível" e o "factível" ou os meios e recursos para a objetivação social (Bourdieu, 1981). Além disso, torna centrais no esquema analítico do autor as relações entre a "história incorporada", a "história reificada" e a "história objetivada" (Bourdieu, 1980b), bem como temas metodologicamente conexos, tais como a noção de "trajetória" (e não "história de vida") (Bourdieu, 1986), de "reconversão", etc. ${ }^{5}$

Metodologicamente, a principal decorrência destes princípios é a necessidade de se operar com uma abordagem, simultaneamente, tanto "perspectivista" quanto "objetivista" e, com isso, apreender, por um lado, os princípios de classificação e luta pela legitimação no mundo social, inclusive as classificações "cultas" ou "eruditas" (ou seja, a geração do "pensável") e, por outro lado, as condições de sua emergência e realização social (legitimação, oficialização, institucionalização), conforme as respectivas posições e estruturas de capital (Bourdieu, 1984: 31 e passim; 1981). Uma das principais conseqüências disso é que as dicotomias que se apresentam como oposições teóricas e metodológicas nas ciências sociais, vinculadas a princípios de classificação e legitimação ou a filosofias sociais, tais como, por exemplo, a ênfase no "indivíduo"/"pessoa" ou "sociedade", "interioridade" ou "exterioridade",

5 Para maiores detalhes sobre estas formulações, seus fundamentos teóricos e confrontos com outras abordagens, ver Bourdieu (1979 e 1980) e para uma apresentação não analítica mas informativa relativamente às alteraçōes destas bases teóricas e ênfases conceituais no decorrer da carreira do autor, inclusive os efeitos de suas origens e trajetória social e intelectual nisso, ver Bourdieu (1987: particularmente 13-46) e Bourdieu \& Wacquant (1992). 
"subjetividade" ou "objetividade", "simbólico" ou "real", entre outras, são tomadas como "falsos problemas" decorrentes de "debates ético-políticos" (Bourdieu, 1982b: 35/36). Uma segunda implicação metodológica é que as oposições entre metodologias e técnicas de trabalho (por exemplo, entre as "quantitativas" e as "qualitativas") perdem o sentido, visto que sua validade se define relativamente aos requerimentos do objeto de estudo e as "condenações metodológicas" são uma forma de justificar a precariedade do domínio do conjunto das metodologias (Bourdieu, 1989b: 25).

Tudo isso, evidentemente, tem implicações profundas no que tange ao ensino das ciências sociais, das quais cabe pelo menos elencar algumas: a) nesta concepção, as ciências sociais se definem única e exclusivamente como problemas analíti$\cos$, que incluem a pesquisa empírica e excluem todos os demais usos que se possa fazer das mesmas; b) seu ensino, além da inculcação de seus instrumentos e das disposições necessárias para utilizá-los, requer que se rompa com "as rotinas do ensino pedagógico" e seu "ritual da exposição canônica" (Bourdieu et al, 1968: 10); c) este "saber sociológico" não pode ser visto como "uma soma de técnicas ou como um capital de conceitos, separados ou separáveis de sua utilização na pesquisa", mas como a "interiorização dos princípios da teoria do conhecimento sociológico" (Bourdieu et al, 1968: 10/11); d) para romper com a "epistemologia espontânea", através do "racionalismo aplicado", é necessário inverter "a relação entre a teoria e a experiência" e chegar ao "primado epistemológico da razão sobre a experiência" (idem: 91); e) não é possível separar a epistemologia da teoria e da metodologia; f) a relevância do objeto de pesquisa é dada exclusivamente por sua fundamentação teórica e nunca pela sua "importância social ou política" (Bourdieu, entre outros, 1989b: 20); g) os conceitos servem somente para operacionalizar os pressupostos teoricamente fundamentados e não como "instrumentos teóricos" em si mesmos (Bourdieu, 1989b: 27); h) como nas ciências sociais as "rupturas epistemológicas" são também "rupturas com as crenças fundamentais do grupo", praticar a "dúvida radical em sociologia é pôr-se um pouco fora da lei", ou seja, "romper com o próprio grupo" (Bourdieu, 1989b: 39). ${ }^{6}$

\section{2 - Os "problemas" da abordagem de Bourdieu e os "nossos problemas"}

Boa parte dos problemas abordados sumariamente a seguir, dentro de uma perspectiva geral, está presente em qualquer esforço na introdução e adoção de esquemas analíticos das ciências sociais numa realidade distinta daquela em que os mesmos foram gerados. Porém, no caso específico da abordagem de Bourdieu, estes problemas assumem determinadas especificidades e, o que é pior, em geral se agravam.

As dificuldades começam pelo fato de que a "agenda de problemas" contida em seu esquema analítico não é, necessariamente e de fato, a mesma dos interessados em sua utilização. Isso porque sua concepção de ciências sociais, seus pro-

6 Para maiores desdobramentos e detalhes, ver particularmente Bourdieu et al (1968) e Bourdieu (1989b). 
blemas teóricos, fundamentos epistemológicos e as derivações metodológicas são outros e, portanto, perdem ou mudam de sentido se os interessados em sua utilização partem de outras perspectivas, com seus "problemas", objetivos e preocupações próprios. Dito de outro modo: o instrumental somente existe efetivamente em relação ao objeto em que poderá ser utilizado.

$\mathrm{Na}$ medida em que qualquer referencial teórico é o produto da história escolar e intelectual dos respectivos países produtores e exportadores de cultura escolar, quando exportados para outras situações que têm outra tradição escolar, tendem a ser reinterpretados e redefinidos, em confronto e/ou amálgama com esta tradição escolar. ${ }^{7}$ Porém, além da inexistência de uma tradição escolar, numa situação de dependência cultural, a disponibilidade e confrontos entre esquemas analíticos ou referenciais teóricos se tornam bem mais confusos e complexos. Ocorre que, como as elites "intelectuais" (e escolares) brasileiras, em boa medida, são escolarizadas no Exterior ou então em alguns centros brasileiros, mas de qualquer modo através da absorção de determinados esquemas analíticos ou referenciais teóricos importados, em geral com adesão exclusiva a alguns em detrimento de outros, existem dificuldades ou mesmo a impossibilidade de "comunicação horizontal". Isso, em primeiro lugar, porque as afiliações tendem a ser "verticalizadas", em geral com o pólo dominante situado em diferentes países centrais, com tradições escolares e, particularmente, no que tange às ciências sociais, completamente distintas. Em segundo lugar, como as adesões se dão mais com base no reconhecimento do que numa escolha seletiva, e esta adesão não significa necessariamente o dominio dos fundamentos epistemológicos do esquema analítico utilizado e muito menos a compreensão e a comparação com os demais, os confrontos dos resultados da utilização destes esquemas analíticos tendem a se tornar inócuos, visto que incomunicáveis, ou então, por conveniência institucional, meramente ritualísticos.

No caso específico de Bourdieu, este esquema analítico tende a redefinir e aprofundar estes problemas por uma série de razões e com diversas conseqüências. Um dos problemas mais gerais, embora já estivesse presente nos primórdios das ciências sociais, é o da construção do objeto de estudo. Porém, as novas condições em que se apresenta são completamente distintas e no limite, tendem a impor uma barreira intransponível para a apreensão e utilização parcializada, como se costuma fazer com os demais esquemas analíticos. Ocorre que, no caso de Bourdieu, mais que uma teoria, trata-se de um modo de encaminhar uma série de problemas pró-

7 Como é sabido, um dos melhores exemplos destas reinterpretações de filosofias e esquemas analíticos europeus, no que tange às ciências sociais, é a sociologia norte-americana. Mas para o que está em pauta, casos como o norte-americano não têm nenhuma importância, como parâmetro de comparação, visto que as condições são outras, a começar pela inexistência de uma tradição escolar entre nós; por não haver um grupo étnico que se pretenda como o "guardião" da cultura, ideologia e ética dominantes, como nos E.U.A. (Collins, 1979). Para algumas interpretações e criticas a esta sociologia norte-americana pelo próprio Bourdieu, ver, por exemplo, Bourdieu (1987: 50-52 e 1991).

Em síntese, no nosso caso, não se trata de algo semelhante à França, Inglaterra, Alemanha, onde, segundo o próprio Bourdieu (1982: 227), a "personalidade intelectual" da "sociedade - ou melhor das classes cultivadas desta sociedade - é constituído ou reforçado pelo sistema de ensino, profundamente marcado por uma história singular e capaz de modelar os espíritos dos discentes e docentes pelo conteúdo e pelo espirito da cultura que transmite como pelos métodos segundo os quais efetua esta transmissão" (do que resultam, por exemplo, o "positivismo" inglês, o "racionalismo" francês, etc.). 
prios das ciências sociais no sentido do "racionalismo aplicado", o qual deslegitima explicitamente as demais possibilidades e, portanto, torna-o exclusivo, tendo como fundamento último a mencionada "utopia racionalista".

Este "racionalismo radical" e reflexivo, se por um lado pode representar um salto para as ciências sociais, por outro lado significa também um obstáculo para sua apreensão parcial, provocando uma série de desdobramentos. O primeiro é que, nestes termos, embora exista socialmente, não é legítima qualquer relação com as ciências sociais, enquanto tais, ou seus objetos, como uma relação "prática", orientada por uma adesão "ontológica" e não analítica, ou seja, é pressuposta uma ruptura radical entre a "razão prática", objeto de estudo, e a "razão analítica" (Bourdieu, 1980) e como visto, a legitimidade das ciências sociais e seus produtos, necessariamente, se tornam completamente desvinculados da legitimação maior ou menor que o tema eventualmente transformado em objeto de estudo possa ter em termos sociais e culturais, ficando restrita ao campo científico e a suas regras próprias. Por exemplo, neste esquema analítico, não há a possibilidade de se opor, normativamente, uma "não-dominação" às formas de dominação que estruturam e dão a dinâmica das lutas sociais. Ora, é sabido que, nas nossas condições, a quase totalidade dos que investem na aprendizagem e na utilização das ciências sociais visam, basicamente, a busca de "sentido", ou seja, a fundamentação de "utopias" ou então, outros objetivos mais diretamente "pragmáticos". Além disso, boa parte das noções de ciências sociais em voga tende a legitimar esta perspectiva.

Este "descolamento" das ciências sociais frente às relações "práticas" com o universo social também remonta aos seus primórdios e, de modo mais geral, ao processo de autonomização relativa das diferentes dimensões da sociedade moderna, com seus princípios fundadores e dinâmicas próprias, destacado particularmente por Weber (1984). Mas no caso de Bourdieu, as barreiras, inclusive estrategicamente impostas à apreensão e utilização parcializada de suas premissas e conceitos (através, por exemplo, da recusa de uma exposição meramente "teórica" das bases de seu trabalho e do "didatismo" ${ }^{8}$ se tornam bem mais dificilmente transponíveis. Como visto, a pressuposição de uma autonomia da lógica das ciências sociais, calcada no "racionalismo aplicado", abrange tanto a chamada "objetivação do sujeito objetivante", ou seja, as condições sociais e culturais das possibilidades deste conhecimento "racional", como também o controle das possibilidades das interferências das determinações sociais sempre presentes (Bourdieu (1984).

Por outro lado, ocorre um conjunto de dificuldades decorrentes das próprias relações lógicas entre, de um lado, os conceitos entre si e, por outro lado, destes com os pressupostos que os fundamentam epistemologicamente, além de suas relações com o arsenal metodológico que os tornam operacionais. Isso tudo faz com que não apenas a apreensão e utilização deste esquema analítico, mas inclusive a própria leitura da produção sociológica, somente seja possível para quem dispõe de seus próprios códigos (Bourdieu, 1984: 34-52). Dito de outro modo, ao mesmo tempo em que a chamada abordagem "relacional" pressupõe uma "de-substancialização" das categorias empíricas e os princípios classificatórios que as fundamentam, as relações lógicas entre os conceitos e suas premissas tornam inoperantes as ten-

8 Ver, por exemplo, Bourdieu (1987: 66-71 e 1982: 11-52). 
tativas de sua utilização sem o domínio de seu conjunto. A estas dificuldades se acrescem ainda as diferenças de níveis de abstração destes conceitos e premissas, em termos de graus de generalização e de especificidade. Por exemplo, não tem sentido o conceito de "capital", sem se ter presentes suas vinculações com o de "estrutura de capital"; por sua vez, com "posição social", com formação de "classes", com "princípios de classificação", com "formas de dominação", com "legitimação", com "estratégias de reprodução social", com illusio e assim por diante. Mas isso não basta, se não se tiver presentes as relações lógicas que os hierarquiza conforme os respectivos níveis de abstração.

Evidentemente, um tipo de proposta assim, como qualquer proposta, suscita oposições ou ambivalências inclusive nos países de origem, seja no interior da própria sociologia ou então, de disciplinas conexas, como a ciência política, até porque, além dos confrontos conceituais e metodológicos, como destacou Caro (1980: 1171), este tipo de abordagem nos coloca "em presença de uma objetivação de nosso ser social que suscita numerosas reticências", na medida em que "contradiz as representações pré-existentes" e por isso "pode ser vista como uma verdadeira agressão intelectual" que "suscita reações de defesa", podendo levar "à oposição resoluta" ou uma "compreensão seletiva". Dito de outro modo, muitas oposições e críticas têm como fundamento muito mais os requerimentos deste tipo de sociologia quanto à postura e à concepção e usos das ciências sociais, que propriamente problemas de metodologia, visto que transforma as melhores "intenções" e "boas causas" em estratégias de dominação social. Ou seja, além dos problemas de instrumentalização conceitual e metodológica ou uma "dificuldade do intelecto", há também o problema da "dificuldade da vontade" (Bourdieu, 1984: 51).

Mas se a sociologia pode ser definida como "um mecanismo de censura e sublimação" mutuamente legitimado e controlado pelos pares (Bourdieu, 1991: 375), isso pressupõe a existência de uma estrutura acadêmica e escolar que crie as condições para sua existência de fato, para que possibilite o surgimento de estratégias acadêmicas e profissionais neste sentido. Em tais condições de existência de um campo científico e de uma estrutura institucional, o ethos correspondente a esta "sublimação" racionalista e ascética não é uma exclusividade das ciências sociais, sendo constitutivo da própria academia. As próprias análises de Bourdieu da estrutura da academia e do campo escolar consistem num esforço para explicitar o conjunto de princípios de classificação, legitimação e hierarquização em confronto e as estratégias decorrentes do mesmo. Mas o eixo básico de oposição é aquele que tem um pólo no racionalismo, na excelência e hierarquização estritamente escolar e no ethos, estilo de vida ascético e trajetórias sociais correspondentes; e por outro lado, o pólo menos acadêmico e mais "mundano", vinculado mais diretamente ao campo do poder (econômico, político, cultural) e portanto menos racionalista e escolar.

Estes mesmos principios estão presentes nas divisões e oposições entre os próprios cursos e áreas de conhecimento, principalmente o confronto entre, por um lado, os cursos visando a aplicação "prática" de produtos das ciências (medicina, direito, etc.) ou então as "escolas de poder" e por outro lado, os voltados para a investigação científica, com principios de legitimação e critérios de hierarquização distintos e próprios (Bourdieu, 1979, 1982, 1989 e Bourdieu \& Saint Martin, 1987). 
Para o que está em pauta, cabe destacar que as ciências sociais encontram-se entre estes últimos, cuja legitimação não está baseada em suas aplicações "práticas", nem como recurso para estratégias de acumulação de poder. Uma das conseqüências disso é que, deixando-se de lado os trabalhos de Bourdieu sobre a Argélia, a maior parte daqueles sobre a França e em especial os que tomam a educação como objeto, tem na objetivação sociológica da ideologia meritocrática e, inclusive, a utilização das ciências sociais para fundamentar "sociodicéias", um de seus principais objetivos. Ora, nos encontramos numa situação cultural e escolar em que o meritocratismo nunca chegou a emergir como principio estruturante e também não se trata de algo semelhante às condições da Argélia. Desse modo, mais que conceitos, como os de "capital escolar", "científico", etc., é o conceito de "capital social" (Bourdieu, 1980) o é mais pertinente para a maior parte das situações encontradas. Porém, nem sempre é fácil a compatibilização deste tipo de conceito e seus fundamentos epistemológicos com outros esquemas analíticos forjados especialmente para a análise de situações sociais não "modernas e ocidentais" (Coradini, 1995).

A primeira vista, tudo poderia ser reduzido a uma questão de grau. Entretanto, na medida em que os esquemas analíticos não podem ser tomados de modo parcializado, em situações como as do Brasil, são as próprias condições de possibilidade e a "lógica" escolar que entram em pauta. Estas condições e "lógica", que tornam a apreensão e utilização de esquemas analíticos como o de Bourdieu muito difíceis, decorrem de determinantes de diferentes níveis, alguns dos quais devem ser mencionados, pelas conseqüências que têm. Em primeiro lugar, a inexistência (com exceção de algumas "ilhas", em alguns centros) de um campo escolar e acadêmico que possa propiciar o surgimento e estruturação de um ethos e das respectivas regras calcadas em princípios de legitimação "racionalistas". Isso por uma série de razões culturais e institucionais que não podem ser detalhadas aqui, mas que estão diretamente vinculadas à formação e estruturação do ensino superior no Brasil. Em segundo lugar, algo vinculado ao anterior, ou seja, a não-conformação de pelo menos um segmento escolar significativo predisposto e em condições sociais e culturais para encarar e elaborar estratégias de investimentos para o desenvolvimento deste tipo de sociologia, ou seja, sem preocupações "práticas", mas apostando tudo nas possibilidades do "racionalismo aplicado". Além da pouca atratividade desta opção propiciada pelas próprias condições sociais de realização social e profissional e seus efeitos nas opções pela área, o principal determinante disso é a simples inexistência de condições escolares ou de uma academia que possa tornar efetivas as condições da realização do ethos e das regras que este tipo de sociologia requer. Dito em outras palavras, não ocorrem as condições que poderiam tornar pelo menos "interessantes" as estratégias de investimentos neste sentido, visto que não são estes os principais critérios de realização e consagração profissional.

Em sintese, a existência e exercício deste tipo de ciência social pressupõe, como condição básica, a existência efetiva de um campo científico, com sua autonomia relativa, ethos e regras próprias, tendo como principio de legitimidade o racionalismo e isso nunca ocorreu no Brasil. Por exemplo, no que tange ao elemento básico da existência da autonomia relativa, .ou seja, a desvinculação das ciências 
sociais do campo político-ideológico, as próprias posições das esferas melhor profissional e socialmente consagradas, como por exemplo, membros destacados da ANPOCS, são pródigos em demonstrar extensivamente sua inexistência. ${ }^{9}$ Algumas das poucas análises dedicadas a demonstrar a subordinação das ciências sociais às preocupações político-ideológicas, sintomaticamente, foram realizadas por franceses (Pécaut, 1990) e até mesmo por componentes da equipe de Bourdieu (Saint Martin, 1988).

Não cabe aqui entrar numa discussão sobre este tema, mas simplesmente destacar algumas de suas conseqüências para o que está em pauta, ou seja, as condições de utilização do referencial de Bourdieu. Para começar, é muito difícil encontrar sentido na utilização de um referencial que pressupõe como um requerimento básico sua desvinculação de qualquer filosofia social, numa situação na qual a própria estrutura escolar está baseada em outros princípios de legitimação e onde, por exemplo, as próprias concepções de ciências sociais as submetem a uma utilização "prática" (seja por motivaçōes político-ideológicas de profetismo ou então, utilitárias). Evidentemente, este tipo de problema também ocorre em situações como as da França, porém, a "lógica" predominante dos confrontos tem outras bases. Deixando de lado as posições explicitamente em bases epistemológicas não racionalistas, no atual estado do campo acadêmico se legitimam por outros critérios, os confrontos mais acadêmicos tendem a se centrar na capacidade explicativa das diferentes abordagens e, portanto, enquanto problemas conceituais e metodológi$\cos ,{ }^{10}$ mas não abrangendo os próprios fundamentos e objetivos das ciências sociais. Um outro bom exemplo disso são os confrontos com a dita ciência política e suas vinculações com a doxa da política e os conseqüentes esforços de politicólogos mais acadêmicos em incorporar e superar este tipo de crítica, visto que o próprio princípio do racionalismo se mantém como fundamento das ciências sociais e dificilmente pode ser posto em questão, nestas condições.

Portanto, uma das dificuldades mais gerais da adoção de um referencial como o de Bourdieu nas nossas condições é a própria inexistência de um campo científico e sua organização institucional que garantam as possibilidades da realização social do ethos e das regras correspondentes. Conseqüentemente, os princípios e critérios de excelência e hierarquização ou de realização "profissional" vão de encontro às regras mais estritamente acadêmicas e, particularmente, de um referencial teórico como o que está em pauta. A isso se acrescem as condições culturais mais gerais, visto que a mencionada relativa autonomização das esferas sociais, que caracterizam o chamado "mundo moderno", no Brasil não se realizou, pelo menos da mesma forma. A principal conseqüência disso é que os usos das ciências sociais tendem a ser "práticos" ou por "demandas externas" (motivações com base em filo-

9 Mesmo restringindo-se exclusivamente à ANPOCS, os exemplos poderiam ser multiplicados indefinidamente, mas para se tomar apenas um dos mais ilustrativos, ver as exposiçōes na Mesa-Redonda denominada "Teoria e Método e as Ciências Brasileiras da Atualidade", publicadas na Revista Brasileira de Ciências Sociais (jul. de 1991). Simultaneamente com a própria defesa do ensino de "teoria", as concepções de ciências sociais em pauta chegam a defini-las explicitamente em termos "normativos" e "pragmáticos" (ver particularmente a intervençāo de Reis e de Schwartzman).

10 Relativamente ao referencial de Bourdieu, ver, por exemplo, os argumentos das criticas em Rancière et al (1984). 
sofias sociais, em estratégias político-ideológicas, como conformação de identidades sociais, como estratégia de "ilustração" e consagração social, etc.), inclusive porque os critérios de sua legitimação são desta ordem. Sendo assim, uma das estratégias possiveis é a adoção de referenciais teóricos que prescindam ou passem ao largo deste tipo de problema, buscando a legitimação do objeto de estudo através de sua suposta relevância social, no que algumas disciplinas, particularmente a ciência política (para não falar da economia) têm grandes vantagens, devido à chamada "demanda social" por seus produtos.

Mas na medida em que o referencial de Bourdieu passou a ter uma maior legitimidade, aumentaram também o interesse e as tentativas de sua utilização e, conseqüentemente, as dificuldades e malentendidos. Numa primeira fase, a principal "crítica" que the era apresentada se centrava na suposta ênfase na "reprodução social", o que vai de encontro à busca de referenciais calcados em filosofias sociais que valorizam a "transformação". Ou seja, mais que um problema analítico, estava em pauta uma demanda por "utopias", por definição, excluídas do referencial de Bourdieu. Nesta linha, inclusive apresentadores consagrados chegaram a destacar esta ênfase na "reprodução" e portanto, num "certo pessimismo político e social", como um limite do referencial, como é o caso, por exemplo, de Ortiz (1983: 29).

Posteriormente, a tendência passou a ser as tentativas no sentido de sua utilização parcializada. É neste ponto que atuaimente se encontram os maiores problemas e dificuldades. Uma das mais gerais destas dificuldades é a da exigência por parte do esquema analítico de Bourdieu de qualquer filosofia social enquanto premissa e de relação "prática" com o objeto e, por extensão, com o conseqüente prescretivismo, normativismo ou mesmo, profetismo. Na medida em que isso supõe uma ruptura ou suspensão da relação ontológica com o mundo social, sua apreensão e utilização não pode ser parcial, pelo fato de que se trata de perspectivas excludentes e, sendo assim, não é possivel se romper com as doxas e illusio dos respectivos "campos" e muito menos, da "cultura erudita", sem esta ruptura anterior. Isso requer uma posição de "externalidade", que por sua vez supõe um domínio completo das bases epistemológicas do referencial. Requer, ainda, uma abordagem que metodologicamente contemple simultaneamente tanto o "perspectivismo" como o "objetivismo", para que consiga apreender as condições sociais de existência tanto do "pensável" como de sua "objetivação social" (Bourdieu, 1980 e 1984).

Esta mesma impossibilidade de apreensão parcializada não se restringe aos fundamentos epistemológicos e premissas gerais, mas abrange também o conjunto da estrutura conceitual da abordagem e suas relações com os métodos e técnicas de investigação. Como já mencionado, tanto os conceitos como seus desdobramentos metodológicos perdem seu sentido se não estiverem referidos às suas relações lógicas entre si e com as premissas que lhe dão fundamento, o que não significa que a opção da utilização de conceitos e métodos não esteja vinculada ao objeto de estudo. Porém, esta utilização seletiva supõe, necessariamente, o dominio destas relações lógicas entre premissas, conceitos, metodologias e indicadores a ser utilizados.

Embora esta não seja uma exclusividade do referencial teórico de Bourdieu, a diferença principal é que no caso, mais que uma teoria, trata-se da formulação de 
um esquema analítico mais rigoroso no sentido destas relaçöes lógicas entre premissas, conceitos, encaminhamentos metodológicos e evidências empiricas. Conseqüentemente, aqueles usos que se fazem de outros referenciais, como, por exemplo, o de Marx, de Weber, etc., que consistem numa apreensão e uso de algumas de suas idéias gerais ou "conceitos", de modo desvinculado do restante, freqüentemente transformando o autor numa espécie de "ícone" para servir meramente como argumento de autoridade, ou então, a utilização de conceitos como "escudos" nas lutas pela afirmação de idéias ou posições apriorísticas, se tornam bem mais difíceis. O resultado disso é a ilusão de que se "usa" determinado autor ou abordagem, sem o domínio do conjunto de seus fundamentos e estrutura conceitual, como se fosse uma espécie de "chave dos segredos" e cujo critério de escolha do "autor preferido" tendiam a se pautar pelo "gosto". Neste ponto também, ao mesmo tempo em que o esquema analítico de Bourdieu pode significar um avanço para as ciências sociais, representa também um obstáculo para sua apreensão parcializada, até porque ele deslegitima os "ismos". Ou seja, nesta ótica, como visto, as "escolhas" conceituais e metodológicas parciais e excludentes, por exemplo, por metodologias "qualitativas" ou "quantitativas" ou então por esta ou aquela abordagem, se constitui numa "confissão de incompetência", visto que decorrem do não-domínio de seu conjunto.

Uma das conseqüências mais imediatas e generalizadas disso é uma apreensão não apenas parcializada, mas também uma espécie de "retradução" das premissas e conceitos. Para mencionar apenas alguns exemplos de problemas mais frequentes: a) a chamada abordagem "relacional", em sua apreensão fora de seus fundamentos epistemológicos e metodológicos, acaba sendo reduzida ou convertida em algo como relações no sentido físico; b) a apreensão parcializada daqueles conceitos mais gerais e abstratos e, portanto, mais simples, mas por isso mesmo, não operacionais, tais como os "campos", o habitus, etc., como se os conceitos fossem operacionais sem suas premissas e suas relações lógicas entre si; c) por outro lado, o que é o resultado também da própria concepção generalizada de "teoria" que se difundiu nas ciências sociais locais, ou seja, "teoria" como equivalente de abstração e generalidade e não enquanto estrutura conceitual e metodológica, epistemológica e logicamente fundamentada. Certamente, é desse tipo de concepção de "teoria" que decorre mais uma dificuldade nesta apreensão do referencial em pauta, ou seja, a tendência de se tomar os conceitos como "coisas", equivalentes a fenômenos reais e não enquanto instrumental analítico.

Por fim, algo que pode parecer irônico, ou seja, a adoção de referenciais teóricos tidos como "críticos" pelo pólo dominado das ciências sociais, em oposição ao establishment, não é uma exclusividade brasileira. Este é um fenômeno que ocorre inclusive em paises culturalmente dominantes e com uma forte tradição escolar, como os E.U.A., onde também a posição dominada, ao adotar referenciais teóricos "alternativos" às ciências sociais dominantes, acabam nem sempre se instrumentalizando metodologicamente para enfrentar a legitimidade destas (Bourdieu, 1991: 383). Ocorre que em situações como as do Brasil, frente às condições de ensino das ciências sociais, a apreensão e utilização de referenciais como o de Bourdieu, que pode ser visto como "crítico", ao supor uma melhor escolarização $€$ profissionalização das ciências sociais, pode ter um efeito de "elitização da crítica". 
Portanto, conjuntamente com a discussão dos esquemas analiticos das ciências sociais e as condições de sua elaboração, é necessário também incluir as condições escolares e profissionais necessárias para a sua apreensão e utilização. No nosso caso, se inclui particularmente as condições de ensino e exercício e também as concepções de ciências sociais em voga.

\section{Referências bibliográficas}

BOURDIEU, P. \& SAINT MARTIN, M. "Agrégation et ségrégation; Le champ des grandes écoles et la champ du pouvoir". In: Actes de la Recherche en Sciences sociales, (69), sep., 1987.

BOURDIEU, P. \& WACOUANT, L. J. D. Réponses. Paris: Seuil, 1992.

BOURDIEU, P. A Economia das Trocas Simbólicas. Săo Paulo: Perspectiva, 1982.

- Choses Dites. Paris: Minuit, 1987.

- . "Décrire et prescrire; note sur les conditions de possibilité et les limites de l'efficacité politique". In: Actes de la Recherche en Sciences Sociales, mai, 1981.

BOURDIEU, P. "Epilogue; "On the possibility of a field of world sociology". In: —— \& COLEMAN, J. S.

Social Theory for a Changing Society. New York: Sage, 1991.

BOURDIEU, P. et al. Le Métier de Sociologue. Paris: Mouton-Bordas, 1968.

- Homo Academicus. Paris: Minuit, 1984.

—— . "Introdução a uma sociologia reflexiva". In: —— o Poder Simbólico. Lisboa: Difel, 1989b.

— . "L'illusion biographique". In: Actes de la Recherche en Sciences Sociales, (62/63), 1986.

_ . La Distinction; Critique sociale du jugement. Paris: Minuit, 1979.

— . La Noblesse d'État; Grandes écoles et esprit de corps. Paris: Minuit, 1989.

__ . "La science et l'atualité". In: Actes de la Recherche en Sciences Sociales, (61), mars, 1986.

_ـ . "La spécificité du champ scientifique et les conditions sociales du progrs de la raison." In: Sociologie et Societés, VII (1), mai, 1975.

__ . "Le champ scientifique". In: Actes de la Recherche en Sciences Sociales, (2-3), juin, 1976.

- . "Le mort saisit le vif; Les relations entre l'histoire réifiée et l'histoire incorporée". In: Actes de la Recherche en Sciences Sociales, (32/33), 1980b.

- Le Sens Pratique. Paris: Minuit, 1980.

— Leçon Sur la Leçon. Paris: Minuit, 1982b.

_ - "Les Sciences Sociales et la Philosophie". In: Actes de la Recherche en Sciences Sociales, (47/48), juin, 1983.

— . "Penser la politique". In: Actes de la Recherche en Sciences Sociales, (71/72), mars, 1988.

CARO, J.-Y. "La sociologie de Pierre Bourdieu: éléments por une théorie du champ politiquen". In: Revue Française de Science Politique, 30 (6), déc., 1980.

COLLINS, R. The Credential Society; An historical sociology of education and stratification. San Diego: Academic Press, 1979.

CORADINI, O. L. "'Grandes Familias' e Elite 'Profissional' na Medicina no Brasil". In: Cadernos de Ciência Politica, UFRGS, 1995.

ORTIZ, R. "A procura de uma sociologia da prática". In: —— . (org.). Pierre Bourdieu. São Paulo: ÁtiCa, 1983.

PÉCAUT, D. Os Intelectuais e a Politica no Brasil; Entre o povo e a naçāo. São Paulo: Ática, 1990.

RANCIRE, J. et al. L'Empire du Sociologue. Paris: La Découverte, 1984.

SAINT MARTIN, M. "A propos d'une rencontre entre chercheurs; sciences sociales et politique ao Brésil". In: Actes de la Recherche en Sciences Sociales, (71/72), mars, 1988.

VÁRIOS. Mesa-Redonda. In: Revista Brasileira de Ciências Sociais, 16 (6), jul. de 1991.

WEBER, M. Economía y Sociedad; Essbozo de sociología comprensiva. México: Fondo de Cultura Económica, 1984. 